\title{
TRANSFORMATION TEXTURES IN A CONTROLLED \\ ROLLED Nb-V STEEL
}

\author{
R.K. Ray*, M.P. Butrón-Guillén and J.J. Jonas \\ Department of Metallurgical Engineering, McGill University, \\ 3450 University St., Montreal, Quebec, H3A 2A7, Canada \\ *Department of Metallurgical Engineering, Indian Institute of \\ Technology, Kanpur 208016 (India)
}

\begin{abstract}
The transformation textures produced by the controlled rolling of a $\mathrm{Nb}-\mathrm{V}$ steel are compared with bcc textures predicted analytically from those of a cold rolled fec Ni30Co alloy of comparable stacking fault energy. The calculated textures show very good agreement with experimental ferrite textures produced from the steel rolled $75 \%$ in the $\gamma$ no-recrystallization range before transformation, and there does not seem to be any variant selection in this case. However, variant selection is likely when ferrite transformation takes place from more heavily deformed austenite (90\% reduction) and also during martensite formation. In addition to the $\mathrm{Cu}$ and Bs components of the $\gamma$ rolling texture, the $S$ component also contributes significantly to the formation of the main components of the transformation texture.
\end{abstract}

\section{INTRODUCTION}

During the controlled rolling of steel, the parent $\gamma$ phase develops a crystallographic texture which is later acquired by the phase or phases produced by the transformation. Experimental difficulties generally preclude measurement of the texture of the austenite of conventional steels 
prior to transformation. Hence, indirect methods, such as computer simulations, have been used to study texture development during austenite processing. Because of the orientation relationships linking the parent and product phases, it is possible to infer the parent texture from the texture of the product phase. For steels, there are three relationships which relate the austenite $(\gamma)$ orientation to that of the transformed ferrite $(\alpha)$ or martensite $\left(\alpha^{\prime}\right)$ [1-4]. These are described in Table 1.

Table 1 Orientation relationships between $\gamma$ and $\alpha$ or $\alpha^{\circ}$

\begin{tabular}{|cccc|}
\hline $\begin{array}{c}\text { Orientation } \\
\text { relationship }\end{array}$ & $\begin{array}{c}\text { Lattice } \\
\text { correspondence } \\
\text { relation }\end{array}$ & $\begin{array}{c}\text { Number of } \\
\text { alternatives }\end{array}$ & $\begin{array}{c}\text { Total } \\
\text { number of } \\
\text { variants }\end{array}$ \\
\hline Kurdjumov- & $\{111\}_{\gamma} \|\{011\}_{\alpha}$ & 4 & 24 \\
Sachs (KS) & $\begin{array}{c}<011>_{\gamma} \|<111>_{\alpha} \\
(\text { Twin-related } \\
\text { variants) }\end{array}$ & 3 & 2 \\
\hline $\begin{array}{c}\text { Nishiyama- } \\
\text { Wassermann }\end{array}$ & $\begin{array}{c}\{111\}_{\gamma} \|\{011\}_{\alpha} \\
\text { (NW) }\end{array}$ & 4 & 3 \\
\hline Bain (B) & $\{001\}_{\gamma} \|\{001\}_{\alpha}$ & 3 & 3 \\
& $<100>_{\gamma} \|<110>_{\alpha}$ & 1 & 3 \\
\hline
\end{tabular}

Any serious study of transformation textures should take into consideration the following two questions, namely: (i) with what accuracy can transformation textures be predicted theoretically? and (ii) what is the origin (in the $\gamma$ ) of the important components of the a transformation texture? It is the aim of the present paper to highlight some recent findings in this area. For this purpose, a $\mathrm{Nb}-\mathrm{V}$ steel was control rolled in the $\gamma$ norecrystallization region, to retain the rolling texture, and then transformed into either ferrite or martensite. The experimental textures of these two transformation products are compared with those derived analytically by transforming the cold rolling textures of an fec Ni30Co alloy. The latter has a stacking fault energy (SFE) of $\sim 72 \mathrm{~mJ} / \mathrm{m}^{2}$ [5], which compares very well with the SFE of $\gamma$ iron $\left(\sim 75 \mathrm{~mJ} / \mathrm{m}^{2}[6]\right)$. Finally, an attempt is made to 
determine the origin (in the $\gamma$ ) of the important transformation texture components that are observed experimentally.

A comprehensive review of various aspects of transformation textures in steels has recently been published [7]. The different simulation techniques and their usefulness and limitations are described in detail in two other publications $[5,8]$.

\section{EXPERIMENTAL}

The experimental steel had the following chemical composition: $0.18 \% \mathrm{C}, 1.35 \% \mathrm{Mn}, 0.034 \% \mathrm{Nb}$, and $0.003 \% \mathrm{~V}$. It was obtained from Stelco Steel, Hamilton, Ontario in the form of a $5 \mathrm{~cm}$ thick plate. Small blocks of size $20 \mathrm{~cm} \times 12 \mathrm{~cm} \times 5 \mathrm{~cm}$ were cut from this plate, austenitized at $1250^{\circ} \mathrm{C}$ in an electric furnace, and then control rolled in the $\gamma$ no-recrystallization range to a finishing temperature of $850^{\circ} \mathrm{C}$ and to reductions of $75 \%$ and $90 \%$. The rolling experiments were carried out at the Metals Technology Laboratories of the Department of Energy, Mines and Resources, Ottawa. During rolling, the temperature was monitored by inserting $\mathbf{P t}-\mathbf{P t R h}$ thermocouples at the centres of the steel plates. The rolled steel samples were air-cooled to room temperature to produce the ferrite/pearlite structure. One sample of the $90 \%$ rolled material was quenched in water immediately after controlled rolling to produce martensite.

Crystallographic textures were measured for all the above materials on mid-thickness planes using the ODF method. ODF's were also measured on the mid-thickness planes of the $70 \%$ and $90 \%$ cold rolled $\mathrm{Ni} 30 \mathrm{wt} \%$ Co alloy [9]. The latter ODF's are assumed to be representative of the austenite rolling textures. They were transformed according to the three orientation relationships of Table 1 to yield predictions of the bec a textures [8]. Equal weights were given to all variants of the transformation being simulated.

\section{RESULTS AND DISCUSSION}

The $\Phi_{1}$ sections of the experimental ODF's for the $\mathrm{Nb}-\mathrm{V}$ steel, control rolled to $75 \%$ and $90 \%$ reduction, followed by air cooling, are presented in Figs. 1a) and b). The general features of these ODF's are similar, with orientation distribution maxima located at nearly the same positions in orientation space. The major components of the transformation texture, in 
both cases, are $\{332\}<113>$ and $\{113\}<110>$. However, the ODF for the $90 \%$ rolled material is nearly twice as intense as that of the $75 \%$ rolled sample (maximum $\mathrm{f}(\mathrm{g})$ 's of 6 to 7 compared to maxima of 3.0 to 3.4 in the latter case).

Figs. 2a) and b) depict the $\phi_{2}$ sections of the experimental ODF's of the $\mathrm{Ni30Co}$ alloy, cold rolled at room temperature to $70 \%$ and $90 \%$ reduction, respectively. These ODF's show that the major components of the deformation texture are $\{112\}<111>(\mathrm{Cu}),\{110\}<112>(\mathrm{Bs})$ and $\{123\}<634>(\mathrm{S})$, as expected for medium SFE materials [10]. These components are relatively intense (maximum $\mathrm{f}(\mathrm{g})$ 's of 9 to 11 ) after $70 \%$ deformation. Further rolling to $90 \%$ increases their intensities to maximum $\mathrm{f}(\mathrm{g})$ 's of 12 to 13 .

The $\phi_{1}$ sections of the bcc ODF's obtained by transforming the above two fcc ODF's according to the Kurdjumov-Sachs relationship (see Table 1) are shown in Figs. 3a) and b). The NW-derived ODF's are detectably more intense than the KS-derived ones, in keeping with their respective numbers of variants (see Table 1), but are not shown here. Similarly, the ones deduced by the Bain relation are much sharper than either of those calculated using the other relationships.

The general features of the texture for the $75 \%$ control rolled steel (Fig. 1a) are similar to those predicted by transforming the texture of the $70 \%$ rolled Ni30Co alloy (see Fig. 3a). By contrast, the texture of the $90 \%$ control rolled steel (see Fig. 1b) is considerably more intense than that of the corresponding KS related predicted texture (Fig. $3 \mathrm{~b}$ ).

It is generally believed that the transformation of ferrite from austenite takes place according to the KS relationship, even after heavy deformation [11, 12]. The intensities of the textures of the $70 \%$ and $90 \%$ cold rolled Ni30Co alloy displayed only minor differences, as did the corresponding textures predicted according to the KS relationship. The appreciable difference in severity between the two transformation textures in the experimental steel for the two rolling reductions is expected to arise from differences in the sharpness of the austenite rolling textures, which could not be measured.

A close look at the ferrite texture produced from the experimental steel rolled $90 \%$ in the $\gamma$ no-recrystallization range before transformation (see Fig. 1b) and the corresponding predicted ferrite texture (see Fig. 3b) 
shows that, although the severities of the $\{332\}<113>$ component are comparable, the $\{113\}<110>$ component is appreciably more intense in the experimental, as compared to the predicted texture. This indicates that some kind of variant selection is taking place during transformation, which may be a function of the amount of deformation in the $\gamma$ range and/or of the relative thickness of the finish rolled plates. Although it is generally believed [7] that there is no variant selection in steels during ferrite formation, the present results clearly point to such a possibility under specific experimental conditions.

An example of the texture of the martensite produced from the control rolled steel is presented in Fig. 4. Although, as a first approximation, this texture appears similar to the corresponding ferrite texture (see Fig. 1b), there are some intensity maxima in the former which are rather weak in the latter, and vice versa. There is also an appreciable difference in the relative intensities in different $\phi_{1}$ sections compared to those of the corresponding predicted ferrite texture (see Fig. $3 b$ ). Since the locations of the major and minor components of the texture, in all cases, are similar in orientation space, the observed intensity differences clearly point to some kind of variant selection during transformation. Such conclusions have been drawn by several previous workers, as discussed in Ref. 7 .

It has been suggested that the main components of the transformation texture, namely, the $\{332\}<113>$ and $\{113\}<110>$, originate from the $\{110\}<112>(\mathrm{Bs})$ and $\{112\}<111>(\mathrm{Cu})$ components of the texture, respectively, in the rolled $\gamma$ phase [7]. To verify this, the orientations corresponding to the three major texture components of the cold rolled Ni30Co alloy were used to simulate the main components of the $\gamma$ rolling texture. The corresponding bcc orientations were then derived according to the three transformation laws. The results for the KS relationship are presented in a $\phi_{1}$ section ODF in Fig. 5. Similar results were obtained from the other two relationships. In Fig. 5, the locations of the two main transformation texture components have been marked, and the locations of the orientations derived from the $\mathrm{Cu}, \mathrm{Bs}$ and $\mathrm{S}$ positions are also shown. The information contained in the above figure not only supports the important roles of the $\mathrm{Cu}$ and $\mathrm{Bs}$ orientations, it also clearly indicates that the $\mathrm{S}$ component of the $\gamma$ rolling texture contributes significantly to the development of the major components of the transformation texture. 


\section{CONCLUSIONS}

1. Analytically predicted ferrite textures are in very good agreement with experimental ferrite textures produced from steel rolled $75 \%$ in the $\gamma$ no-recrystallization range before transformation.

2. Variant selection does not seem to play a role in the austenite $\rightarrow$ ferrite transformation from $75 \%$ rolled $\gamma$. However, variant selection is likely when ferrite transformation takes place from more heavily deformed austenite (90\%) and also during martensite formation.

3. In addition to the $\mathrm{Cu}$ and $\mathrm{Bs}$ components of the $\mathrm{Y}$ rolling texture, the $S$ component also contributes significantly to the formation of the main components of the transformation texture.

\section{REFERENCES}

1. E.C. Bain, Trans. AIME, 70,25 (1924).

2. G. Kurdjumov and G. Sachs, Z. Physik, 64,325 (1930).

3. Z. Nishiyama, Sci. Rep. Tohoku Univ. , 23,637 (1934).

4. G. Wassermann, Archiv. für das Eisenhütt. , 16 , 647 (1933).

5. R.K. Ray, Ph. Chapellier and J.J. Jonas, Textures and Microstructures , 12,141 (1990).

6. W. Charnock and J. Nutting, Met. Sci.J., 1,123 (1967).

7. R.K. Ray and J.J. Jonas, Int. Mat. Rev. , 35,1 (1990).

8. Ph. Chapellier, R.K. Ray and J.J. Jonas, Acta Metall. Mater., 38, 1475 (1990).

9. R.K. Ray and K. Lücke, Unpublished Research.

10. K. Lücke, Proc. Sixth Int. Conf. on Textures of Materials, The Iron \& Steel Inst. Japan, 1,14 (1981).

11. H. Inagaki, Z. Metallkde. , 75, 510 (1984).

12. H. Inagaki, Z. Metallkde. , 79,716 (1988). 


\section{FIGURE CAPTIONS}

Fig. $1 \phi_{1}$ sections of the experimental ODFs for the controlled rolled $\mathrm{Nb}-\mathrm{V}$ steel (a) reduced $75 \%(\mathrm{~b})$ reduced $90 \%$.

Fig. $2 \Phi_{2}$ sections of the experimental ODFs for the Ni30Co alloy. (a) $70 \%$ cold rolled (b) $90 \%$ cold rolled.

Fig. $3 \phi_{1}$ sections of bcc ODFs obtained by transforming, according to the KS relationship, (a) the ODF in Fig. 2a) (b) the ODF in Fig. 2b).

Fig. $4 \phi_{1}$ sections of the experimental ODF for martensite obtained by quenching the $\mathrm{Nb}-\mathrm{V}$ steel after $90 \%$ reduction in the $\mathrm{Y}$ norecrystallization range.

Fig. 5 Transformation of the $\mathrm{Cu}($ ), Bs ( ) and $\mathrm{S}($ ) fec rolling components using the $\mathrm{KS}$ relationship. 


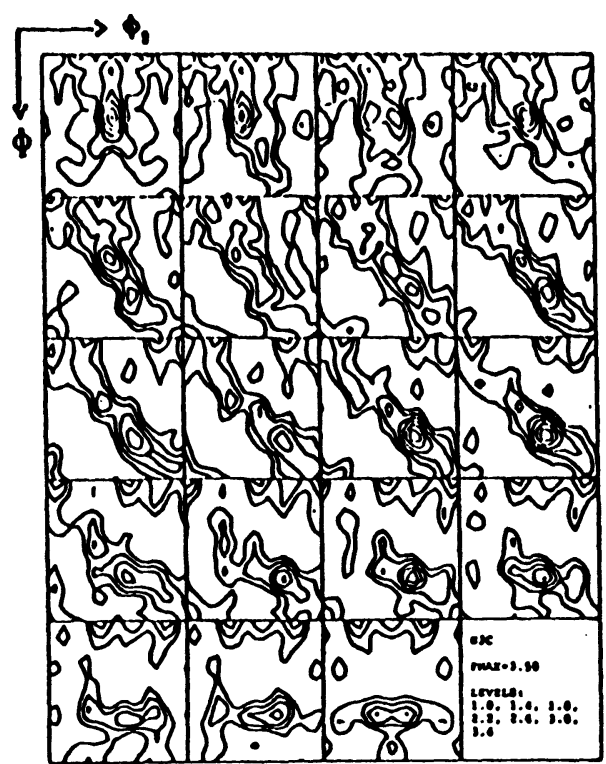

(a)

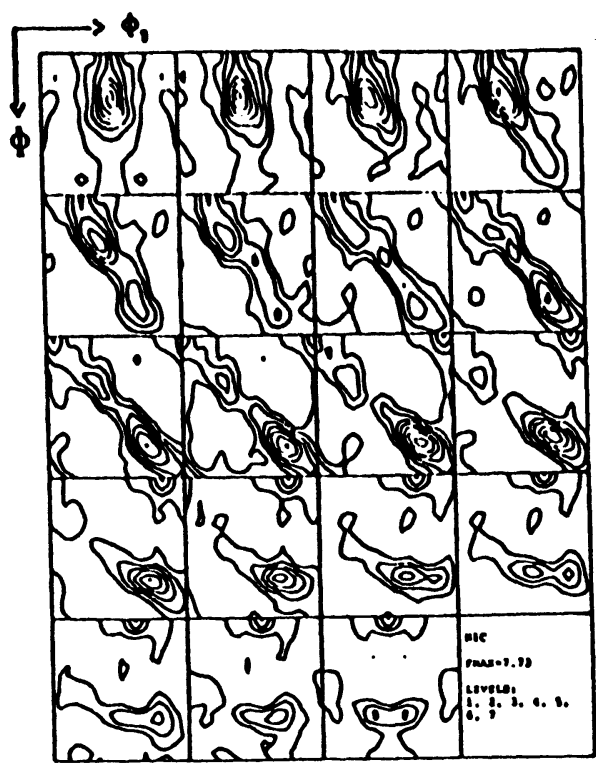

(b)

Fig. $1 \Phi_{1}$ sections of the experimental ODFs for the controlled rolled $\mathrm{Nb}-\mathrm{V}$ steel (a) reduced $75 \%$ (b) reduced $90 \%$.

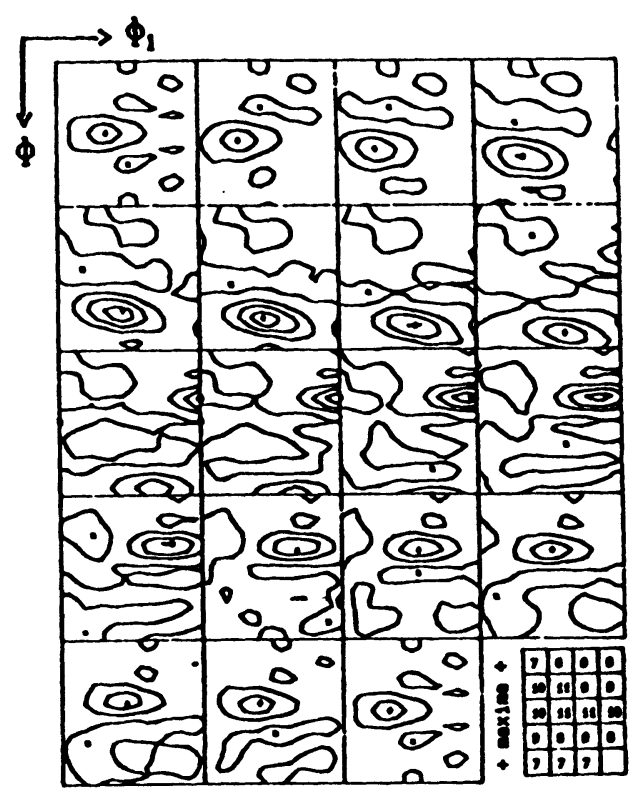

(a)

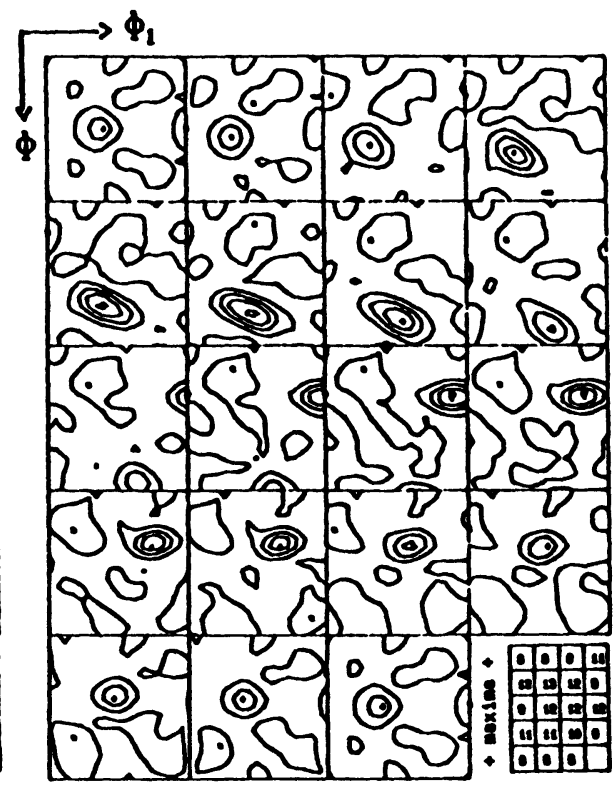

(b)

Fig. $2 \Phi_{2}$ sections of the experimental ODFs for the Ni30Co alloy. (a) 70\% cold rolled (b) $90 \%$ cold rolled. 


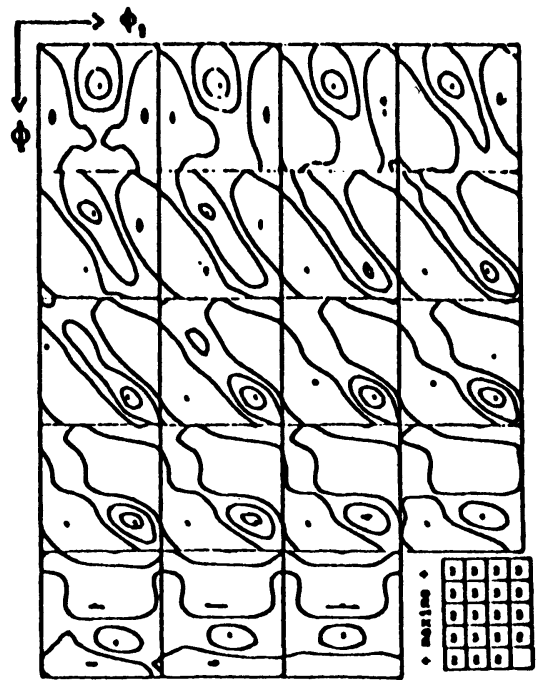

(a)

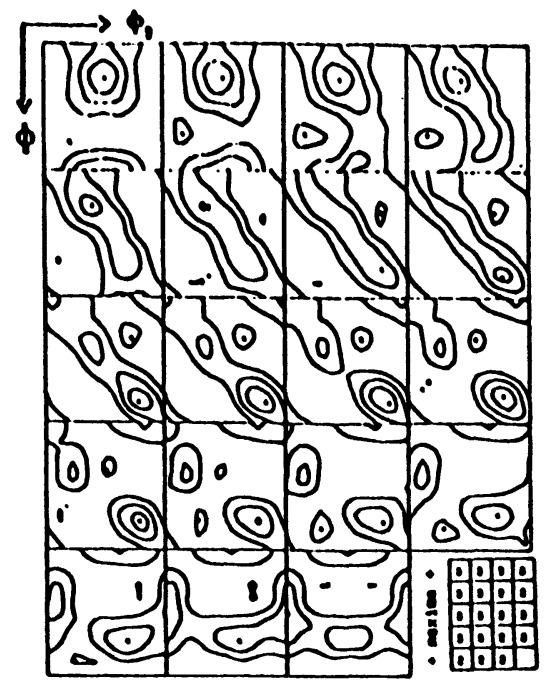

(b)

Fig. 3 \$1 sections of bec ODFs obtained by transforming, according to the KS relationship, (a) the ODF in Fig. 2a) (b) the ODF in Fig. 2b).

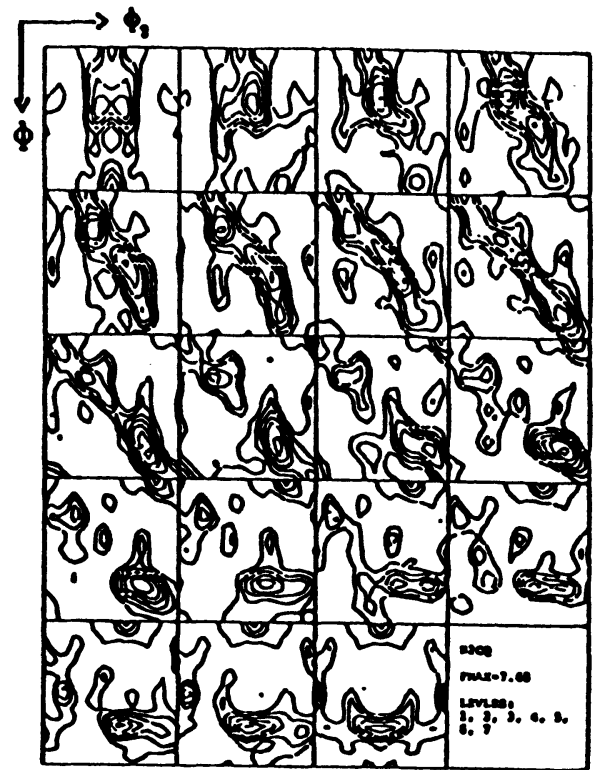

Fig. $4 \Phi_{1}$ sections of the experimental ODF for martensite obtained by quenching the $\mathrm{Nb}-\mathrm{V}$ steel after $90 \%$ reduction in the $\mathrm{Y}$ no-recrystallization range.

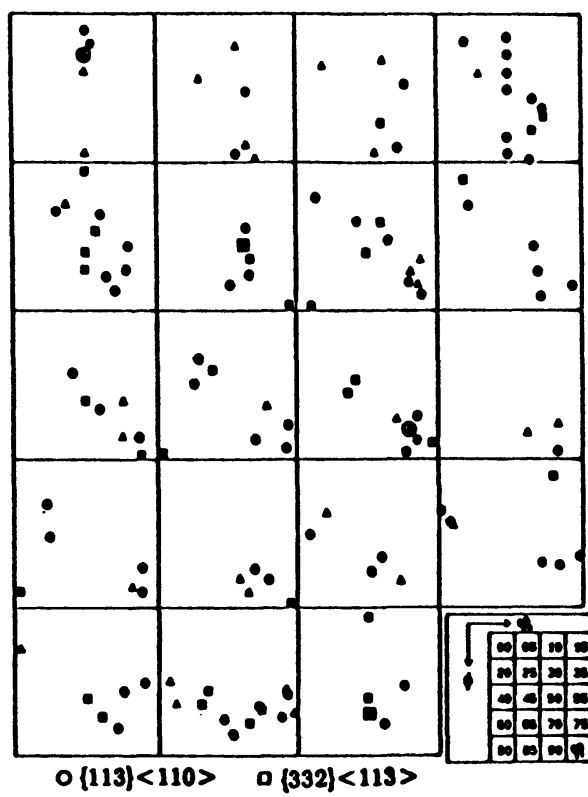

Fig. 5 Transformation of the $\mathrm{Cu}(\Delta)$, Bs $(\square)$ and $S(\bullet)$ fec rolling components using the KS relationship. 